\title{
Nikkah, Dariush (eds): Hand trauma: illustrated surgical guide of core procedures
}

\section{Thieme Verlag, New York, Stuttgart, Delhi, Rio de Janeiro, 2017, 148 pp, 2500 figs, Hardcover, EUR (D) 99,99 EUR (A) 102,80 CHF 115,00, ISBN: 978-3-13-241426-6}

\author{
Alain G. Graftiaux ${ }^{1}$ - Pierre Kehr ${ }^{1}$
}

Received: 6 April 2018 / Accepted: 20 May 2018 / Published online: 4 June 2018

( ) Springer-Verlag France SAS, part of Springer Nature 2018

This book is addressed more particularly to the trainees in surgery and to those which do not make emergency surgery by regular manner. They will find here descriptions clear and quite illustrated of the techniques usually used. This will enable them to manage many emergencies thanks to often simple and tested techniques.

After general information on the clinical examination, the incisions and the various procedures, the various lesions are approached like the lesions of the tendons, nerves, reimplantations, Clerc's Offices and scraps, but also fractures and lesions of the nail.
At the end of each chapter, a short bibliography is presented which makes it possible to look further into the subject.

On the whole it is a clear and concise, easy-to-use little book.

\section{Compliance with ethical standards}

Conflict of interest The authors declare that they have no competing interests. 